This document was prepared in conjunction with work accomplished under Contract No. DE-AC09-96SR18500 with the U. S. Department of Energy.

\title{
DISCLAIMER
}

This report was prepared as an account of work sponsored by an agency of the United States Government. Neither the United States Government nor any agency thereof, nor any of their employees, nor any of their contractors, subcontractors or their employees, makes any warranty, express or implied, or assumes any legal liability or responsibility for the accuracy, completeness, or any third party's use or the results of such use of any information, apparatus, product, or process disclosed, or represents that its use would not infringe privately owned rights. Reference herein to any specific commercial product, process, or service by trade name, trademark, manufacturer, or otherwise, does not necessarily constitute or imply its endorsement, recommendation, or favoring by the United States Government or any agency thereof or its contractors or subcontractors. The views and opinions of authors expressed herein do not necessarily state or reflect those of the United States Government or any agency thereof. 


\section{THERMAL ANALYSIS OF SIMULATED SLURRY MIX EVAPORATOR SAMPLES}

Russell E. Eibling

Troy H. Lorier

October 2004

Immobilization Technology Section

Savannah River National Laboratory

Aiken, SC 29808
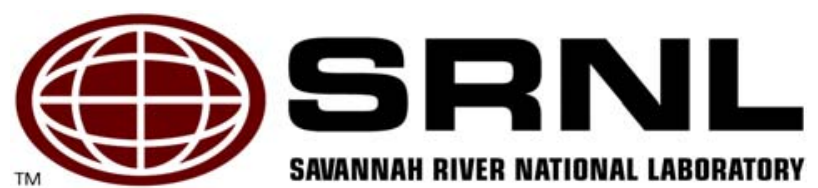
This page was intentionally left blank 
Key Words:

DWPF,

Thermogravimetric Analysis, Differential Scanning Calorimetry

Retention:

\section{THERMAL ANALYSIS OF SIMULATED SLURRY MIX EVAPORATOR SAMPLES}

Russell E. Eibling

Troy H. Lorier

October 2004

Immobilization Technology Section Savannah River National Laboratory Aiken, SC 29808

Prepared for the U.S. Department of Energy Under Contract Number DEAC09-96SR18500

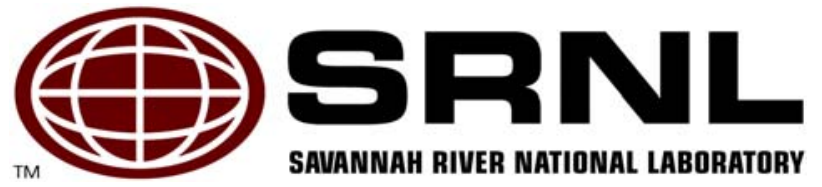




\section{EXECUTIVE SUMMARY}

This report documents the results of applying thermal analysis methods to the characterization of the properties of Slurry Mix Evaporator (SME) product samples as a function of temperature. The goal of the research program was to determine if various thermal analysis methods could aid in measuring melter feed melt rate, study the impact of post SME additions of formic acid, and aid in developing a better understanding of melter cold cap chemistry. The thermal analysis methods tested in this program included Differential Scanning Calorimetry (DSC), Thermogravimetric Analysis (TGA), and Accelerating Rate Calorimetry (ARC). The samples used in the study were from a study on the impact of acid stoichiometry and redox on melt rate. ${ }^{1}$

Application of the thermal analysis methods to SME products provides an excellent means of exploring the fundamental chemical processes occurring within the DWPF melter feed as it transitions from melter feed to the glass product. Based upon the data described in this report:

- The SME product exhibits one major exothermic event when heated from 100 to $1000^{\circ} \mathrm{C}$.

- The exothermic process is the reaction between formate and nitrate and is probably initiated by the melting of a formate salt.

- The dried SME product passes through two major weight loss events when heated from 100 to $1000{ }^{\circ} \mathrm{C}$.

- The first weight loss event is associated with the exothermic formate-nitrate reaction.

- The second weight loss event is probably the decomposition of oxalate.

- No strong evidence of a specific melt point was observed making the use of these methods for melt rate determination unlikely.

- DSC, TGA and ARC data is useful for understanding the cold cap chemical processes and could assist in developing more detailed cold cap chemistry models.

Additional research using thermal analysis methods could significantly increase our understanding of the melting process and thereby improve our capabilities at predicting the impact of feed compositional changes on the melter process.

The information developed through the application of thermal analysis methods can significantly improve our understanding of the reactions/processes occurring within the DWPF melter cold cap. This information can also be used in improving the chemistry in models of the melter cold cap and aid in forecasting the impacts of changes in feed composition on melter operation. Therefore, additional work on thermal analysis in the following areas is recommended.

- Complete work on developing sensitivity curves for the Netzsch DSC measurements to allow measurement of the heats of reaction for processes occurring within simulated DWPF feed samples.

- Develop thermal information on alternate salts that could form or are present in the DWPF melter cold cap.

- Develop tests to confirm the presence of intermediate compounds in samples heated to different cold cap conditions (intermediate temperatures for different lengths of time).

- Complete integration of the TGA system with the mass spectrometer to allow continuous monitoring of the vapor composition exiting the Netzsch instrument.

- Interface the Agilent on-line gas chromatograph with a mole sieve column to the Netzsch instrument to allow measurement of hydrogen generation during TGA measurements.

- Transfer the results of the thermal analysis testing to researchers working on Cold Cap modeling to aid in improving such models. 


\section{TABLE OF CONTENTS}

EXECUTIVE SUMMARY iii

LIST OF FIGURES $\quad$ V

LIST OF TABLES $\quad \mathrm{V}$

LIST OF ACRONYMS vi

1.0 INTRODUCTION AND BACKGROUND 1

2.0 THERMAL ANALYSIS METHODS 1

2.1 Differential Scanning Calorimetry (DSC) 1

2.2 Thermogravimetric Analysis (TGA) 2

2.3 Accelerating Rate Calorimeter (ARC) 3

2.4 Evolved Gas Analysis (EGA) 4

3.0 RESULTS

3.1 DSC Results

3.2 TGA Results $\quad 7$

3.3 ARC Data $\quad 10$

3.4 EGA Results 12

4.0 CONCLUSIONS 13

5.0 RECOMMENDATIONS/PATH FORWARD 15

6.0 REFERENCES

7.0 ACKNOWLEDGEMENTS 19 


\section{LIST OF FIGURES}

Figure 2-1 Typical DSC Result from SME Samples ................................................... 2

Figure 2-2 Typical TGA Result from SME Samples....................................................... 3

Figure 3-1 DSC Curves for SME Products at different acid addition levels ........................... 5

Figure 3-2 Typical DSC curve for melting of a crystalline solid (gold)............................... 7

Figure 3-3 TGA results for SME product samples at different acid addition levels ............... 8

Figure 3-4 Comparison of the derivatives of the TGA curves for Sodium Oxalate and SME

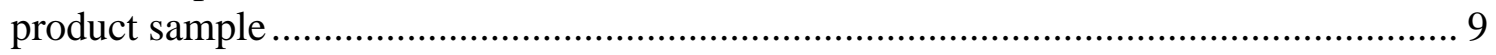

Figure 3-5 Temperature Results for the ARC runs ................................................................. 10

Figure 3-6 Pressure Results for the ARC Runs .............................................................. 11

\section{LIST OF TABLES}

Table 3-1 DSC data for the major exotherm observed in SME product samples.................... 6

Table 3-2 Melting Points of Salts Potentially Present in SME Product ................................ 6

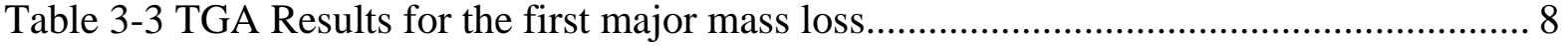

Table 3-4 TGA Results for the second major mass loss ...................................................... 8 


\section{LIST OF ACRONYMS}

ARC

DTA

DSC

EGA

GCMS

SME

STA

TGA
Accelerating Rate Calorimeter

Differential Thermal Analysis

Differential Scanning Calorimetry

Evolved Gas Analysis

Gas Chromatograph-Mass Spectrometer

Slurry Mixer Evaporator

Simultaneous Thermal Analysis

Thermogravimetric Analysis 


\subsection{INTRODUCTION AND BACKGROUND}

The product of the Slurry Mix Evaporator (SME) is a high-solids, aqueous slurry of glass frit and high level waste. This slurry, after definition as acceptable feed, is transferred to the Melter Feed Tank and subsequently fed directly onto the molten glass surface to vitrify the waste. The melter feed forms a structure referred to as the cold cap that transitions from aqueous slurry to molten glass. The material in the cold cap experiences a temperature gradient from sub boiling $\left(50^{\circ} \mathrm{C}\right)$ to $1150^{\circ} \mathrm{C}$. Thermal analysis methods provide an excellent tool for investigating the processes occurring within the cold cap. This report reviews the results obtained to date from the application of thermal analysis methods to SME product samples. The samples used in the study were from a study on the impact of acid stoichiometry and redox on melt rate. ${ }^{1}$ All data reported in this report was produced using non-radioactive simulated waste.

\subsection{THERMAL ANALYSIS METHODS}

Thermal analysis is a group of techniques which monitor a physical property of a material as a function of temperature while applying a controlled temperature program to the material. In essence, the controlled temperature program produces a data curve that can be considered to be a cross-section of the melter cold cap. The techniques applied to the SME samples included differential scanning calorimetry (DSC), thermogravimetic analysis (TGA), and accelerating rate calorimeter (ARC). Work also progressed on setting up equipment to perform evolved gas analysis (EGA). The instruments used were a Netzsch Simultaneous TGA-DSC Model STA-409PC Luxx and a TIAX ARC® Calorimeter. Each of these techniques will be individually described along with their individual capabilities and limitations.

\subsection{Differential Scanning Calorimetry (DSC)}

DSC measures the heat flow and exothermic/endothermic reactions produced as a function of temperature during chemical processes. These processes include phase transitions and chemical reactions. The process can be an endothermic (heat absorbing) or exothermic (heat generating) process. A typical DSC curve for the SME product samples is shown in Figure 2-1. When examining a DSC curve the most important fact to note, is how an exothermic process is indicated on the y-axis. In this report, positive values for the ordinate indicate an exothermic process as marked in Figure 2-1 and negative values indicate an endothermic process. The typical sample size for DSC analysis is small (5$50 \mathrm{mg}$ ) allowing for fast temperature programming rates. The temperature programming range for the Netzsch DSC is 25 to $1500{ }^{\circ} \mathrm{C}$ at rates from 0 to $50^{\circ} \mathrm{C} /$ minute. The atmosphere around the sample can also be controlled by using a vacuum $\left(10^{-7}\right.$ atmospheres) or by purging with an inert or reactive sweep gas.

Several factors must be considered when generating or evaluating DSC data. First, the material to be analyzed must be uniform in composition or as homogenous as possible. The very small sample size means that sampling error due to lack of homogeneity can be very large. The sample size makes it possible to miss a possible heat-related event due to poor sampling or conversely to detect something that is not representative of the bulk material. Second, the shape of the DSC curve is strongly influenced by both the sample properties (particle size, sample amount, etc.) and the instrumental factors (atmosphere, furnace geometry, sample holder geometry and material, heating rate, etc.). ${ }^{2}$ Because of these issues, quantitative evaluation of characteristic temperatures (onset of an endo/exotherm, 
maximum of an endo/exotherm, end of an endo/exotherm) must be conducted from a qualitative point of view. Comparisons between samples run on different instruments can be difficult.

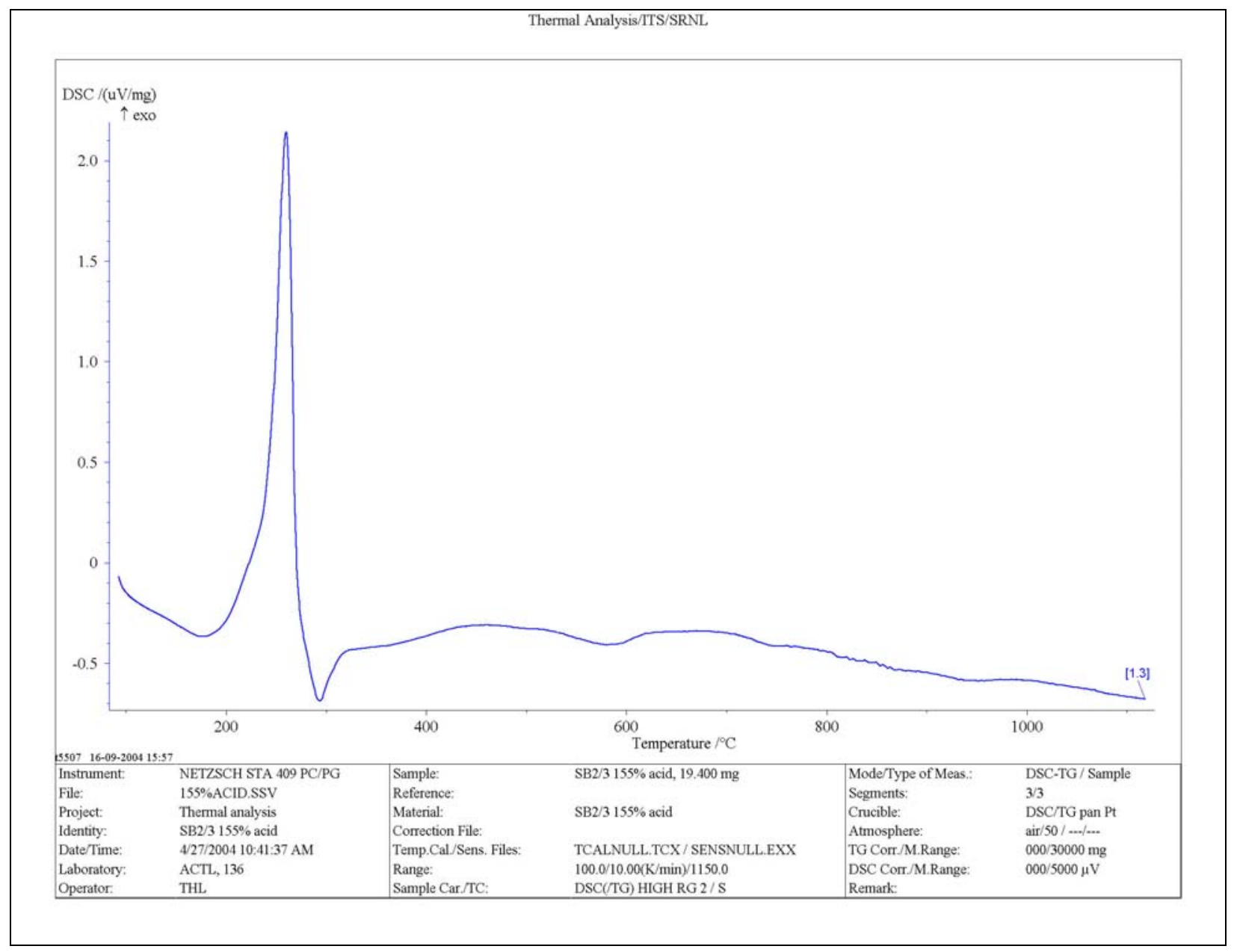

Figure 2-1 Typical DSC Result from SME Samples

\subsection{Thermogravimetric Analysis (TGA)}

Thermogravimetric analysis is the quantitative measurement of weight change as a function of temperature in a controlled atmosphere. TGA is capable of detecting dehydration, oxidation/reduction, and decomposition reactions assuming that a volatile product is produced. Figure 2-2 shows a typical TGA curve for a SME product sample. Also shown in Figure 2-2 is the derivative of the weight loss curve which aids in identifying the temperature at which the maximum rate of weight loss is observed. The typical sample size for TGA can range from small (5-50 mg) up to large (0.5-10 gram) allowing for temperature programming rates to vary from fast to very slow (necessary for large samples). The temperature programming range for the Netzsch DSC is 25 to $1500^{\circ} \mathrm{C}$ at rates from 0 to $50^{\circ} \mathrm{C} /$ minute. The atmosphere around the sample can also be controlled by using a vacuum ( $10^{-7}$ atmospheres), static atmosphere or by purging with an inert or reactive sweep gas. TGA is often combined with EGA since the larger sample sizes combined with slow temperature ramp rates aid with the chemical characterization of offgas composition. 
TGA has issues similar to those mentioned above for DSC with both sampling and with the nature of the data generated. The shape of the TGA curve is strongly influenced by both the sample properties (particle size, sample amount, etc.) and the instrumental factors (atmosphere, furnace geometry, sample holder geometry and material, heating rate, etc.). Because of these issues, quantitative evaluation of characteristic temperatures (onset of mass loss, maximum rate of mass loss, and the end of mass loss) must be conducted from a qualitative point of view. Comparisons between samples run on different instruments can be difficult.

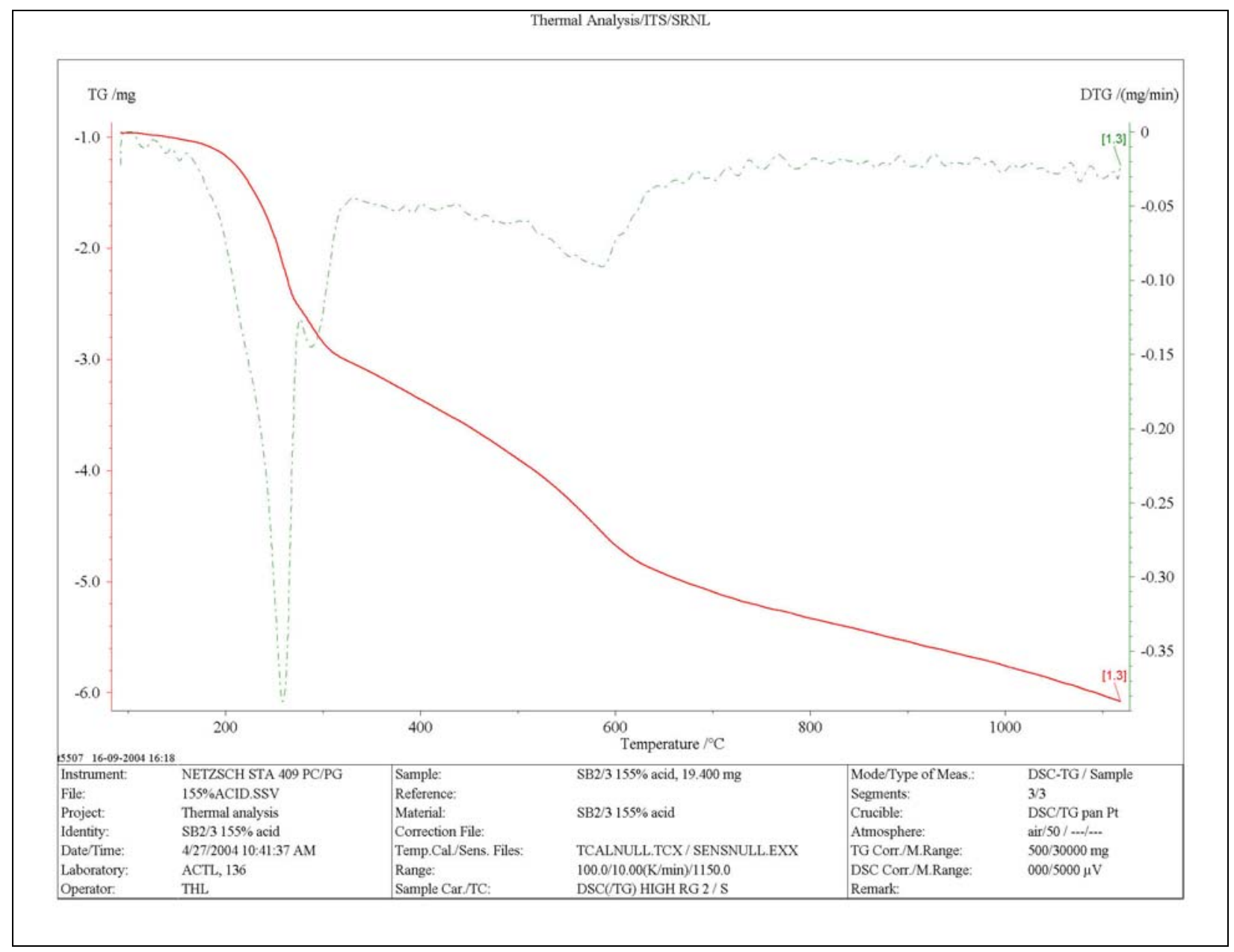

Figure 2-2 Typical TGA Result from SME Samples

\subsection{Accelerating Rate Calorimeter (ARC)}

The ARC is an adiabatic calorimeter capable of monitoring both temperature and pressure of a sample as the temperature of the sample vessel is increased. The ARC is primarily used to test for the presence of hazardous, self-heating runaway reactions. The TIAX ARC ${ }^{\circledR}$ Calorimeter temperature range is 25-500 ${ }^{\circ} \mathrm{C}$ and the pressure maximum is based on the materials of the sample vessel. 


\subsection{Evolved Gas Analysis (EGA)}

Evolved Gas Analysis is based on analyzing the gaseous products produced during a thermal analysis experiment. The gas analysis is usually performed by passing the gas stream to a mass spectrometer but can also be performed by other instrumental methods including online gas chromatography, Fourier transform infrared spectroscopy and other methods. The instruments available for EGA for this study were an Agilent 6890 gas chromatograph interfaced to an Agilent 5893 quadrupole mass spectrometer. As currently configured the gas chromatograph includes a manual gas sampling valve. This allows the researcher to selectively sample at a specific time (temperature) the vapor exiting the thermal analysis equipment. Continuous sampling is not currently available. 


\subsection{RESULTS}

\subsection{DSC Results}

Samples for thermal analysis were obtained from SME product batches prepared using Frit 432 with sludge batch 2 at $35 \%$ waste loading and at varying acid addition levels (140, 155, and 170\% stoichiometry). The SME material was produced to support DWPF melt rate studies. These samples prepared by drying at $85{ }^{\circ} \mathrm{C}$ to remove the bulk of the water present prior to introduction to the Netzsch DSC-TG instrument. The samples were run in the combined DSC-TG mode at $10{ }^{\circ} \mathrm{C} / \mathrm{min}$ heating rate from $80-1100{ }^{\circ} \mathrm{C}$.

The DSC curves for SME product samples show one major exothermic event and the rest of the curve is endothermic in nature. Figure 3-1 shows the DSC curves for different amounts of acid added to sludge batch $2 / 3$ simulant.

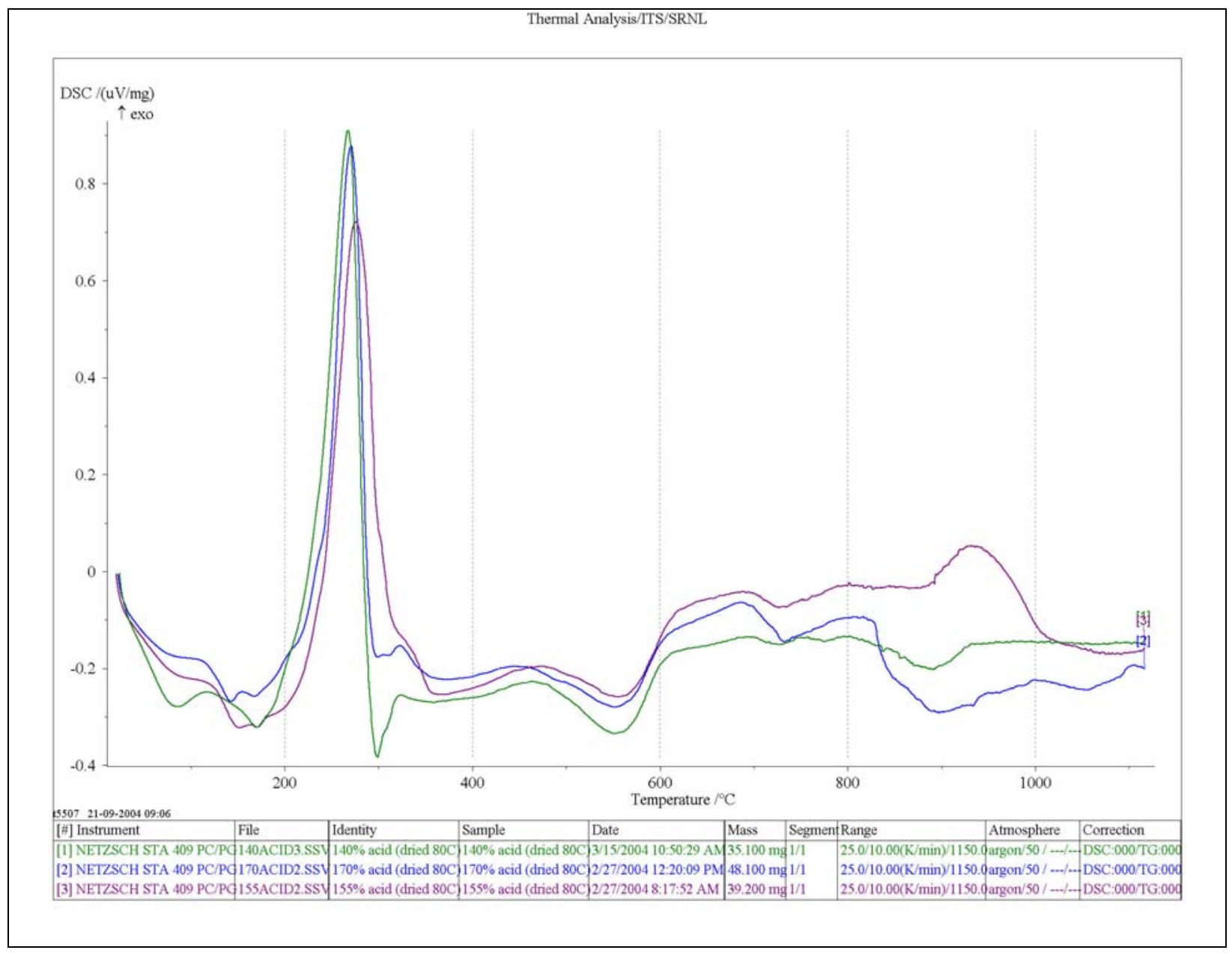

Figure 3-1 DSC Curves for SME Products at Different Acid Addition Levels 
The specific details (start, maxima, area etc) for the major exotherm peak are given in Table 3-1. The sample label is the percent acid stoichiometry used in preparing these melter feeds. The area value can be converted to a heat of reaction value after the instrument has been calibrated.

Table 3-1 DSC data for the major exotherm observed in SME product samples

\begin{tabular}{||c|c|c|c|c|c||}
\hline \hline \multirow{2}{*}{ Sample } & Mass & $\begin{array}{c}\text { Temperature, } \\
\text { Onset }\end{array}$ & Temperature, Maximum & $\begin{array}{c}\text { Temperature, } \\
\text { End }\end{array}$ & Peak Area \\
\cline { 2 - 6 } & $\mathrm{mg}$ & ${ }^{\circ} \mathrm{C}$ & ${ }^{\circ} \mathrm{C}$ & ${ }^{\circ} \mathrm{C}$ & $\mu \mathrm{Vs} / \mathrm{mg}$ \\
\hline $140 \%$ & 37.2 & 226 & 273.4 & 294 & 299.7 \\
\hline $155 \%$ & 39.2 & 236 & 276.3 & 301 & 272.6 \\
\hline $170 \%$ & 48.1 & 244 & 271.1 & 290 & 186.5 \\
\hline
\end{tabular}

The major exotherm which maximizes at about $275^{\circ} \mathrm{C}$ is probably due to the exothermic oxidationreduction reaction between formate and nitrate salts. Evolved gas analysis data obtained on similar melter feed samples at PNNL supports a reaction which generates $\mathrm{CO}_{2}$ and NO in this temperature range. ${ }^{3}$ The mechanism for the reaction may involve the melting of one of the salts to allow intimate contact between the solids. Table 3-2 lists the melting points for the major salts that would be expected to be present in the SME product.

Table 3-2 Melting Points of Salts Potentially Present in SME Product

\begin{tabular}{||c|c|c||}
\hline \hline Compound & Formula & Melting Point, ${ }^{\circ} \mathbf{C}$ \\
\hline Sodium Formate & $\mathrm{NaHCOO}$ & 253 \\
\hline Sodium Nitrite & $\mathrm{NaNO}_{2}$ & 271 \\
\hline Sodium Nitrate & $\mathrm{NaNO}_{3}$ & 308 \\
\hline Sodium Sulfate & $\mathrm{Na}_{2} \mathrm{SO}_{4}$ & 800 \\
\hline Sodium Carbonate & $\mathrm{Na}_{2} \mathrm{CO}_{3}$ & 851 \\
\hline $\begin{array}{c}\text { Sodium } \\
\text { Pyrophosphate }\end{array}$ & $\mathrm{Na}_{4} \mathrm{P}_{2} \mathrm{O}_{7}$ & 880 \\
\hline Sodium Oxalate & $\mathrm{Na}_{2} \mathrm{C}_{2} \mathrm{O}_{4}$ & decomposes \\
\hline \hline
\end{tabular}

From this information and the onset temperatures observed in the DSC curves, the melting of sodium formate seems to be the most likely mechanism for initiation of the exothermic reaction.

The melting of crystalline solids is an endothermic process and will generate specially shaped endothermic peak during a DSC run. ${ }^{4}$ As the solid sample melts the temperature of the sample remains constant producing a nearly linear leading edge of the DSC peak. When the sample has completely melted, the temperature of the sample compared to the reference rises quickly to the oven temperature forming an exponential curve back to the oven conditions. Figure 3-2 illustrates this type of endothermic peak obtained when performing a DSC analysis on a piece of gold foil used as a DSC standard. 
WSRC-TR-2004-00506

Revision 0

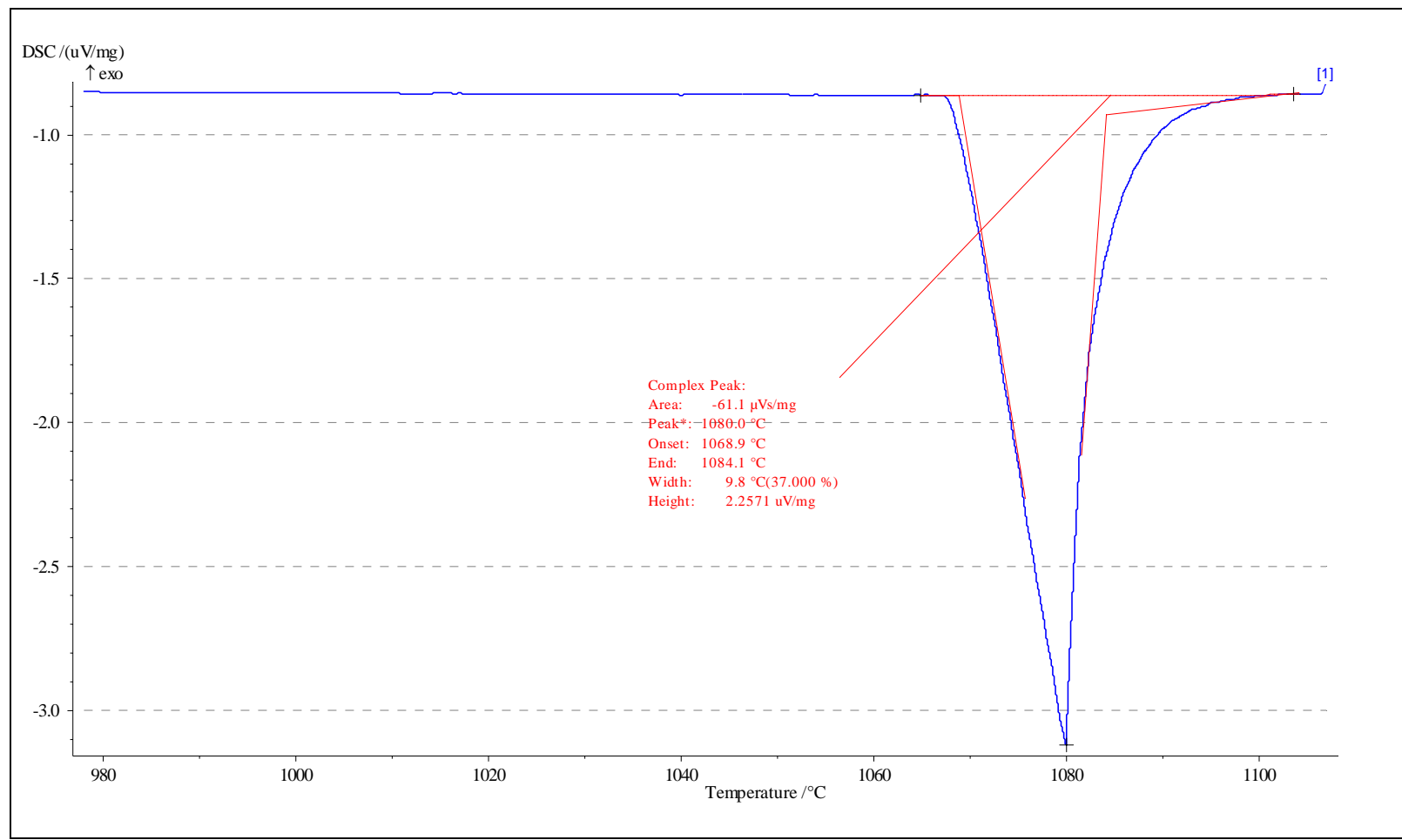

Figure 3-2 Typical DSC curve for melting of a crystalline solid (gold).

An examination of the endothermic portion of the DSC curves for SME product samples in Figure 3-1 does not show any well-defined peaks that match this peak structure. This suggests either that the amount of specific crystalline material is very small or that there are so many small, overlapped peaks it is difficult to see this response.

\subsection{TGA Results}

TGA measures the mass change of a sample due to the generation of a volatile component as a function of temperature. Processes such as melting which do not generate volatile components will not produce a change in the TGA curve. Figure 3-3 displays the TGA curves for three different SME products produced using three different acid levels. The figure shows two different types of curves. The first is a mass loss curve in units of \% mass remaining and the second curve is the derivative of the mass loss curve with respect to time. All of the mass loss curves are similar and the derivative curves indicate that there are two main mass loss events. The first is centered at about $275{ }^{\circ} \mathrm{C}$ and the second at about $560{ }^{\circ} \mathrm{C}$. The first major mass loss in the TGA curves correlates well with the exotherm observed in the corresponding DSC runs for the same samples. The specific details for the first major mass loss are given in Table 3-3. Note that the minimum in the derivative curve corresponds to the temperature at which maximum rate of mass loss is occurring which is the inflection point for that break on the \% mass curve. As previously discussed, this mass loss is probably due to the oxidation-reduction reaction between formate and nitrate leading to the complete destruction of the nitrates in the sample. 
WSRC-TR-2004-00506

Revision 0

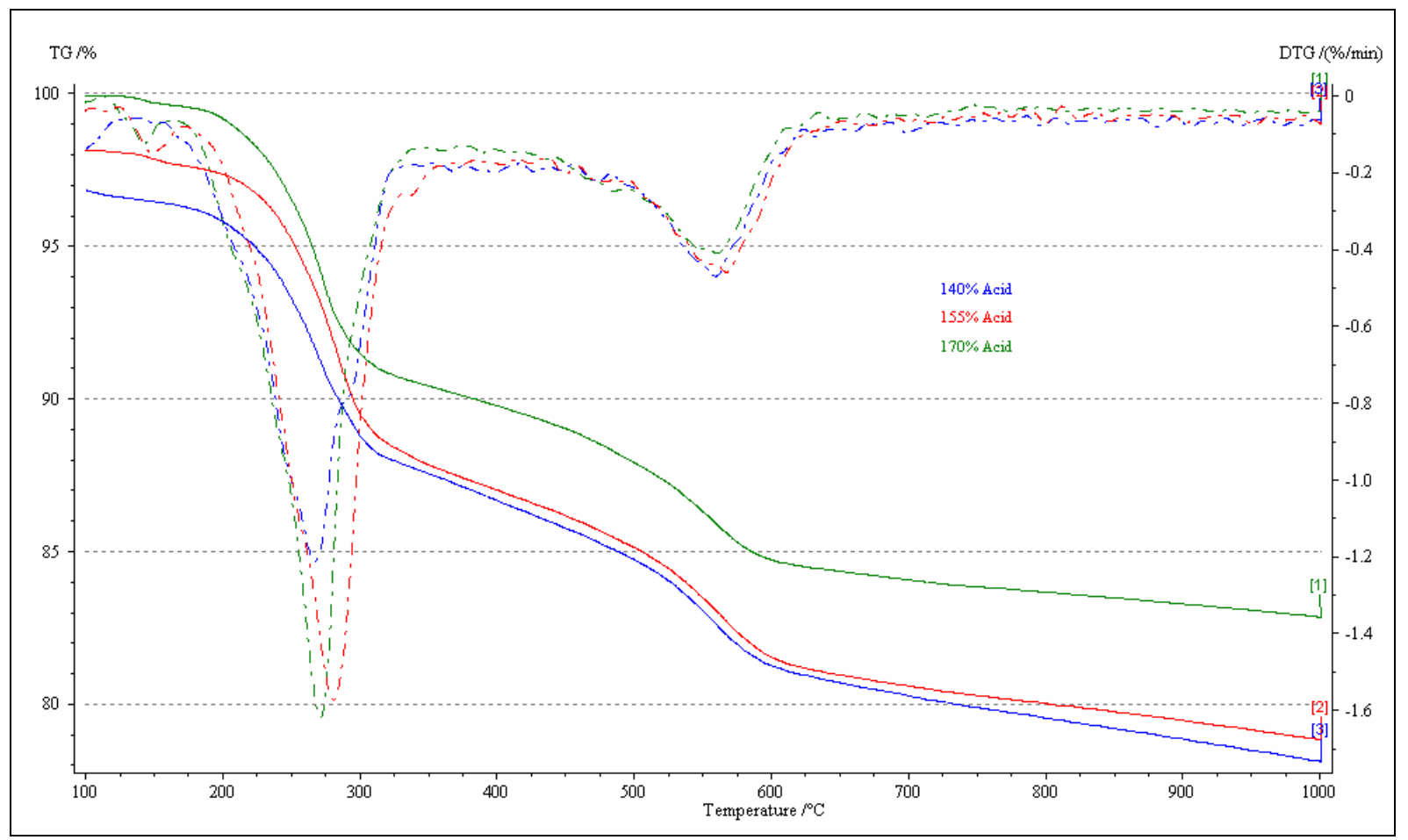

Figure 3-3 TGA results for SME product samples at different acid addition levels

Table 3-3 TGA Results for the first major mass loss

\begin{tabular}{||c|c|c|c|c|c||}
\hline \multirow{2}{*}{ Sample } & Mass & $\begin{array}{c}\text { Mass } \\
\text { Loss }\end{array}$ & $\begin{array}{c}\text { Temperature, } \\
\text { Onset }\end{array}$ & $\begin{array}{c}\text { Temperature, } \\
\text { Maximum Rate loss }\end{array}$ & Temperature, End \\
\cline { 2 - 6 } & $\mathrm{mg}$ & $\%$ & ${ }^{\circ} \mathrm{C}$ & ${ }^{\circ} \mathrm{C}$ & ${ }^{\circ} \mathrm{C}$ \\
\hline $140 \%$ & 37.2 & 10.5 & 234 & 278.4 & 299 \\
\hline $155 \%$ & 39.2 & 10.9 & 248 & 278.6 & 307 \\
\hline $170 \%$ & 48.1 & 9.7 & 236 & 273.4 & 294 \\
\hline
\end{tabular}

The second major mass loss from the TGA curves is located at about $560^{\circ} \mathrm{C}$ and seems to match a minor endotherm on the DSC curves. Table 3-4 lists the measured details for the second mass loss.

Table 3-4 TGA Results for the second major mass loss

\begin{tabular}{||c|c|c|c|c|c||}
\hline \multirow{2}{*}{ Sample } & Mass & $\begin{array}{c}\text { Mass } \\
\text { Loss }\end{array}$ & $\begin{array}{c}\text { Temperature, } \\
\text { Onset }\end{array}$ & $\begin{array}{c}\text { Temperature, } \\
\text { Maximum Rate loss }\end{array}$ & Temperature, End \\
\cline { 2 - 6 } & $\mathrm{mg}$ & $\%$ & ${ }^{\circ} \mathrm{C}$ & ${ }^{\circ} \mathrm{C}$ & ${ }^{\circ} \mathrm{C}$ \\
\hline $140 \%$ & 37.2 & 7.4 & 520 & 565.3 & 602 \\
\hline $155 \%$ & 39.2 & 7.3 & 517 & 569.8 & 604 \\
\hline $170 \%$ & 48.1 & 6.9 & 498 & 563.0 & 596 \\
\hline
\end{tabular}

A comparison of the TGA data from the SME product samples with TGA curves for some of the salts that potentially could present in the samples identified sodium oxalate as the most likely candidate for producing the observed mass loss. Figure 3-4 shows a comparison of the derivative TGA curves for a SME sample and for anhydrous sodium oxalate and indicates a good match for this decomposition. 
WSRC-TR-2004-00506

Revision 0

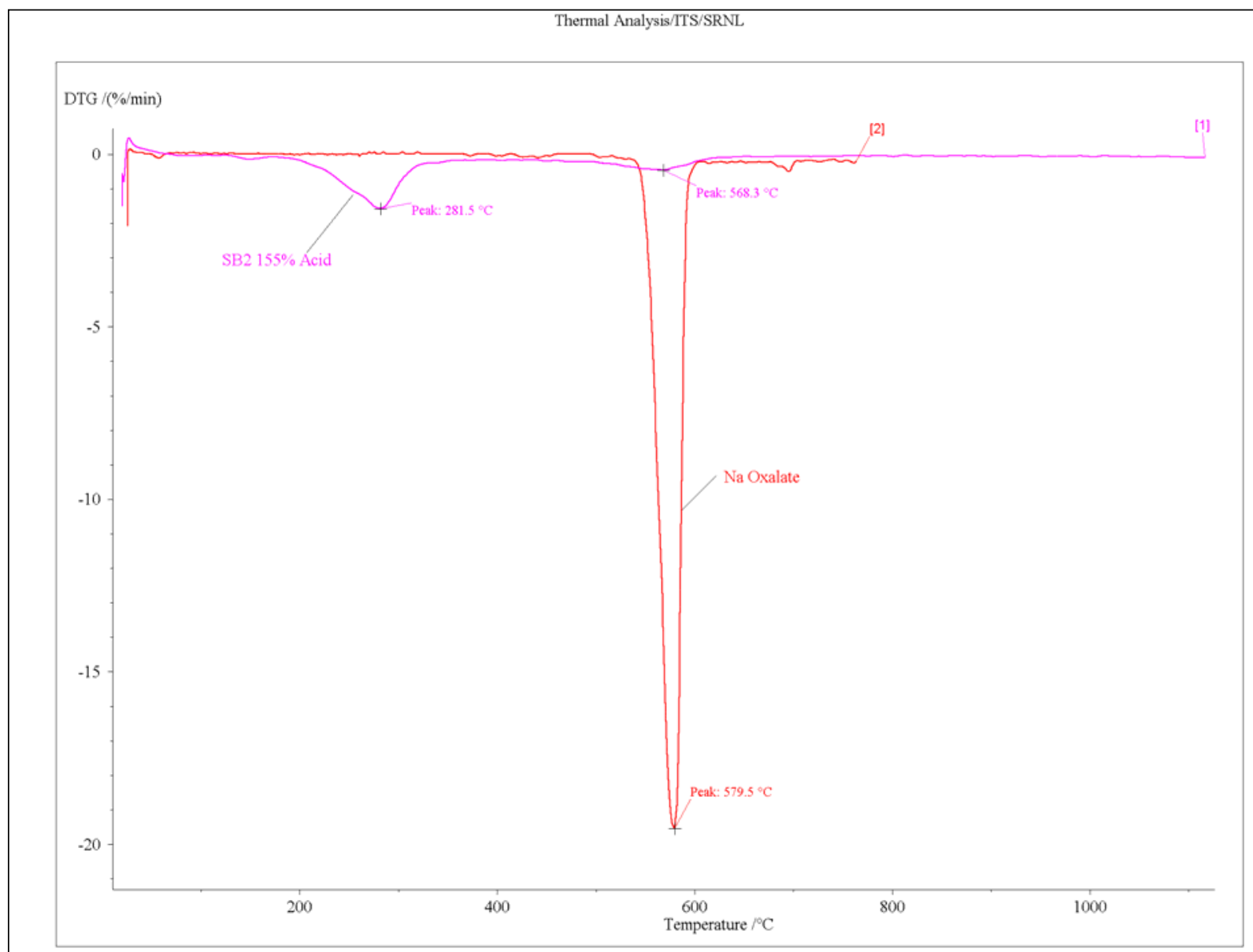

Figure 3-4 Comparison of the derivatives of the TGA curves for Sodium Oxalate and SME product sample

Sodium oxalate was not added to the simulant used to prepare the SME product samples. Therefore, a mechanism to generate the oxalate anion would have to be present. The most likely carbon source is the formate that makes the melter feed samples reducing. The following sequence of reactions seems to be the most likely by which formate converts to oxalate and then on to carbonate and finally $\mathrm{CO}_{2}$.

$$
\begin{aligned}
& 2 \mathrm{NaCOOH} \longrightarrow \mathrm{Na}_{2} \mathrm{C}_{2} \mathrm{O}_{4}+\mathrm{H}_{2}(1) \\
& \mathrm{Na}_{2} \mathrm{C}_{2} \mathrm{O}_{4} \longrightarrow \mathrm{Na}_{2} \mathrm{CO}_{3}+\mathrm{CO}(2) \\
& \mathrm{Na}_{2} \mathrm{CO}_{3} \longrightarrow \mathrm{Na}_{2} \mathrm{O}+\mathrm{CO}_{2}(3)
\end{aligned}
$$

Reaction (1) is reported in the Merck Index as the thermal decomposition reaction for sodium formate. ${ }^{5}$ Reactions (2) and (3) have been well established as part of the use of calcium oxalate monohydrate as a standard for TGA work. ${ }^{6}$ 


\subsection{ARC Data}

Limited exploratory testing of the application of ARC to SME product samples was performed this year. The initial focus of this testing was to determine if the ARC could provide additional insight on SME product melting behavior through pressure measurements and whether the ARC could detect any significant differences due to the addition of formic acid to SME products. The samples tested were SME products with and without additional formic acid added after the SME process was completed.

The ARC was run in a mode similar to the Netzsch analyzer in that the sample temperature and pressure was monitored as the temperature of the heater was increased at a set rate from 25 to $500{ }^{\circ} \mathrm{C}$ starting with a slurry sample of about 1.5 grams. Figure 3-5 displays the temperature results for the SME samples tested. The data plotted on the y-axis is the difference between the rate of change of the sample's temperature and the heater's temperature while the X-axis is the sample temperature. This is similar to a differential thermal analysis (DTA) result. Note that first three curves listed in the figure's legend are plotted against the y-axis scale on the left side of the plot and the red curve (fourth in the list) is plotted against a separate $y$-axis scale on the right side of the plot.

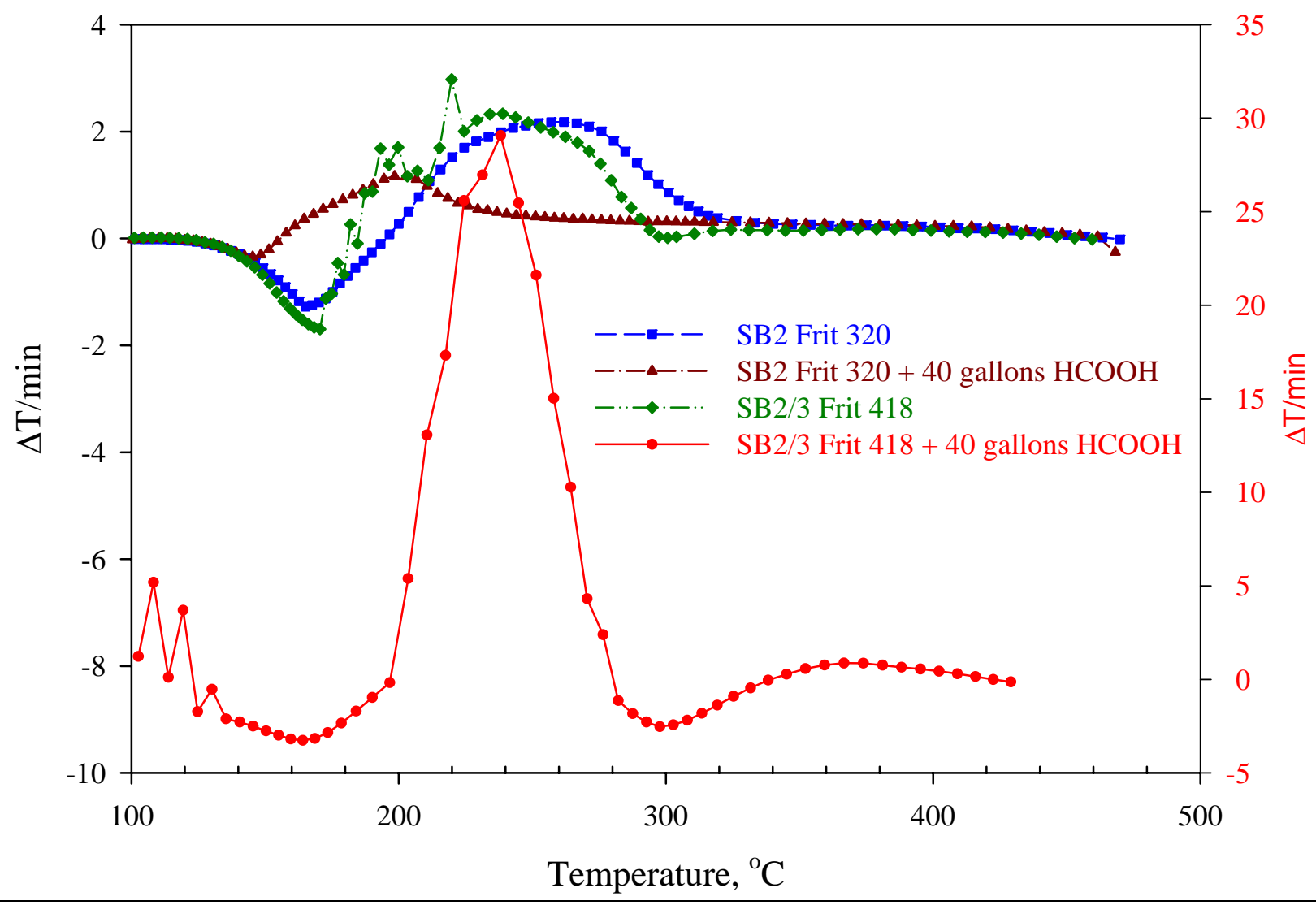

Figure 3-5 Temperature Results for the ARC runs

The fourth curve was also collected using a faster rate of temperature increase $\left(20^{\circ} \mathrm{C} / \mathrm{min}\right.$ versus 10 ${ }^{\circ} \mathrm{C} / \mathrm{min}$ ) than the first three curves. Therefore, the magnitude of the exothermic peak in the fourth curve 
should not be compared to the other three curves. In general, the data shows the same exothermic event that the DSC measurements show with only minor apparent differences between with and without additional formic acid.

Figure 3-6 displays the rate of change in pressure as a function of temperature from the ARC tests. As mentioned above, the magnitude of the peak in the fourth curve should not be compared to the other three curves due to the different heating rate. The first pressure rise is due to evaporation of the water in the aqueous slurry samples and the second pressure rise is due to the exothermic process detected in both the ARC data and the DSC data for SME samples. There do appear to be some qualitative differences in the pressure data and these should be investigated further while insuring that all tests are run under the same test conditions.

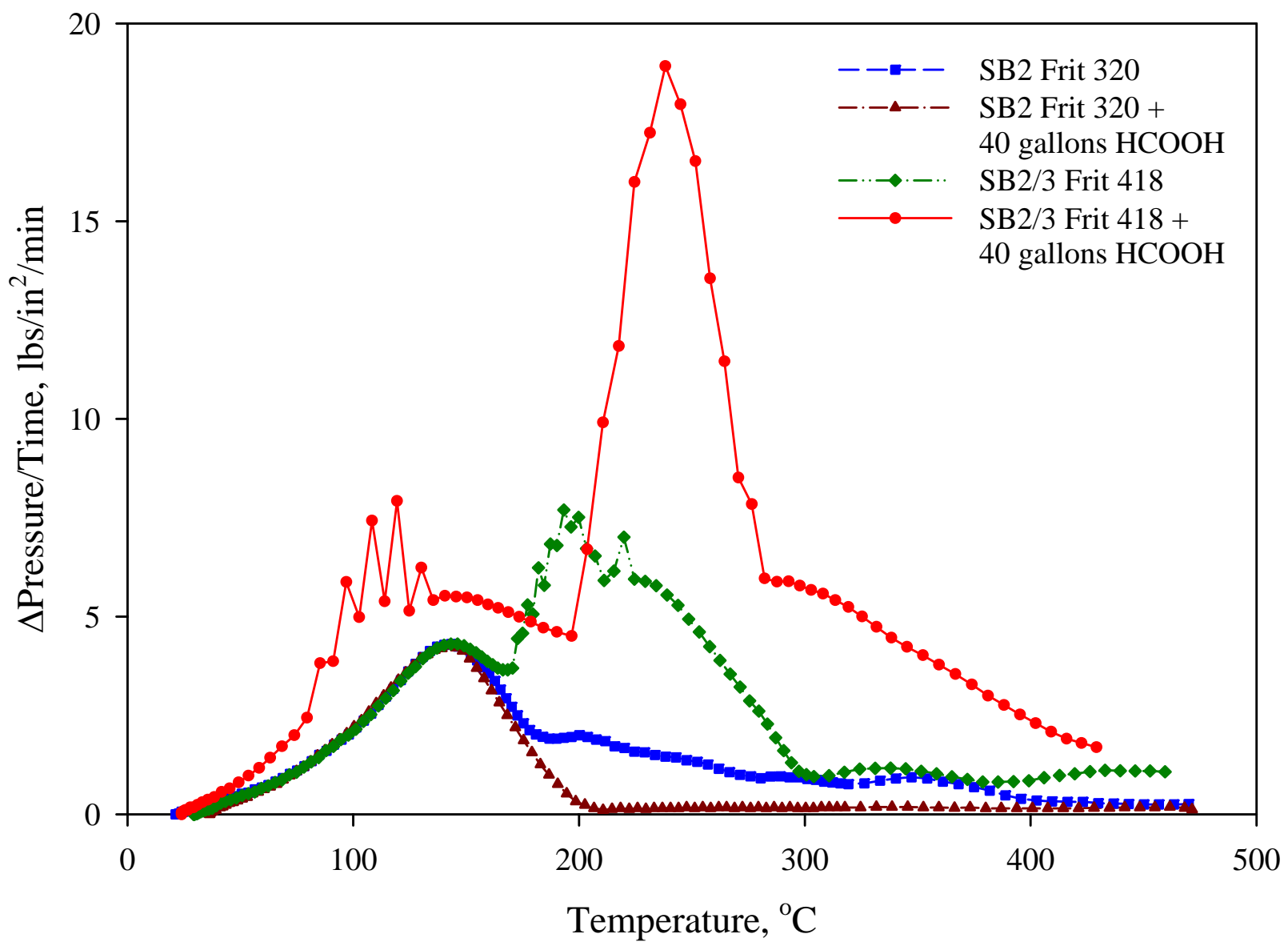

Figure 3-6 Pressure Results for the ARC Runs

Future testing with the ARC should be conducted using samples that have been initially dried to minimize the initial pressure rise. 


\subsection{EGA Results}

Testing of the current sampling interface between the Netzsch DSC/TG instrument and the Agilent gas chromatograph/mass spectrometer has established that injection of a specific portion of the offgas from a thermal analysis run is possible. This will allow gas composition checking on a case by case basis as needed. However, additional modifications will be necessary to allow continuous monitoring of the off gas from a thermal analysis run. 


\subsection{CONCLUSIONS}

Application of the thermal analysis methods to SME products provides an excellent means of exploring the fundamental chemical processes occurring within the DWPF melter feed as it melts within the glass melter. Based upon the data described in this report:

- The SME product exhibits one major exothermic event when heated from 100 to $1000{ }^{\circ} \mathrm{C}$.

- The exothermic process is the reaction between formate and nitrate and is probably initiated by the melting of a formate salt.

- The dried SME product passes through two major weight loss events when heated from 100 to $1000{ }^{\circ} \mathrm{C}$.

- The first weight loss event is associated with the exothermic formate-nitrate reaction.

- The second weight loss event is probably the decomposition of sodium oxalate.

- No strong evidence of a specific melt point was observed making the use of these methods for melt rate determination unlikely.

- DSC, TGA and ARC data is useful for understanding the cold cap chemical processes and could assist in developing more detailed cold cap chemistry models.

Additional research using thermal analysis methods could significantly increase our understanding of the melting process and thereby improve our capabilities at predicting the impact of feed compositional changes on the melter process. 
WSRC-TR-2004-00506

Revision 0

This page intentionally left blank. 


\subsection{RECOMMENDATIONS/PATH FORWARD}

The information developed through the application of thermal analysis methods can significantly improve our understanding of the reactions/processes occurring within the DWPF melter cold cap. This information can also be used in improving the chemistry in models of the melter cold cap and aid in forecasting the impacts of changes in feed composition on melter operation. Therefore, additional work on thermal analysis in the following areas is recommended.

- Complete work on developing sensitivity curves for the Netzsch DSC measurements to allow measurement of the heats of reaction for processes occurring within simulated DWPF feed samples.

- Develop thermal information on alternate salts that could form or are present in the DWPF melter cold cap.

- Develop tests to confirm the presence of intermediate compounds in samples heated to different cold cap conditions.

- Complete integration of the TGA system with the mass spectrometer to allow continuous monitoring of the vapor composition exiting the Netzsch instrument.

- Interface the Agilent on-line gas chromatograph with a mole sieve column to the Netzsch instrument to allow measurement of hydrogen generation during TGA measurements.

- Transfer the results of the thermal analysis testing to researchers working on Cold Cap modeling to aid in improving such models. 
WSRC-TR-2004-00506

Revision 0

This page intentionally left blank. 


\subsection{REFERENCES}

1. Smith, M. E., Miller, D. H., and T. H. Lorier. The Impact of Feed Preparation Acid Stoichiometry and Redox on Melt Rate For the SB3-Frit 418 Feed System. WSRC-TR-200400350, Savannah River National Laboratory, Aiken SC 29808 (July 2004)

2. Weylandt, W. W. Thermal Analysis. $3^{\text {rd }}$ ed., p 228, John Wiley \& Sons, New York (1986).

3. Matyáš, J., Hrma, P. and D. Kim. Melt Rate Improvement for High-Level Waste Glass. PNNL-14003, Battelle - Pacific Northwest Division, Richland, WA 99352 August 2002.

4. Speyer, R. F. Thermal Analysis of Materials. $1^{\text {st }}$ ed., p 50, Marcel Dekker, Inc., New York (1994).

5. O’Neil, M. J., editor. The Merck Index. $13^{\text {th }}$ ed., p 1541, Merck \& Co., Inc., Whitehouse Station, NJ (2001).

6. Simons, E. L. and A. E. Newkirk. "New Studies on Calcium Oxalate Monohydrate- A Guide to the Interpretation of Thermogravimetric Measurements”. Talanta, 11, p. 549 (1964). 
WSRC-TR-2004-00506

Revision 0

This page intentionally left blank. 


\subsection{ACKNOWLEDGEMENTS}

We would like to acknowledge the assistance of Fernando F. Fondeur of the Waste Processing Technology section in acquiring the Accelerating Rate Calorimeter data reported in this report. 
WSRC-TR-2004-00506

Revision 0

This page intentionally left blank. 